\title{
Conditions for the Formation of Wear-Resistant Structures When Strengthening the Surface Layers of Parts
}

\author{
Oleg Cherneta ${ }^{1}$, Vadim Kubich ${ }^{2}$, Roman Voloshchuk ${ }^{3}$, Alexander Sasov ${ }^{1}$, Yuriy Korzhavin ${ }^{1}$ \\ ${ }^{I}$ Dniprovsky State Technical University \\ ${ }^{2}$ Zaporizhsky National Technical University \\ ${ }^{3}$ PAT "Dnipro-Azot" (Kamyans'ke) \\ *Corresponding author E-mail: OCherneta@gmail.com
}

\begin{abstract}
In the given article special attention is paid to the transformation of the structure of average carbon steels, depending on technological methods of strengthening, the identification of factors influencing the emergence of high-strength structures. With the help of microstructural, $\mathrm{X}$ - ray phase studies, microhardness measurements of certain layers, the main technological parameters and modes of reinforcing workings have been identified, new and innovative combined technologies have been proposed. Based on the analysis of a number of existing technological methods of strengthening the surface layer of structural materials, the dynamics of tran sformation of their microstructures was researched. After laser treatment, due to the ultra-high velocity of cooling of crystallized volumes, due to intensive heat removal through the main volume of samples on the surface, a light zone, which is not digestible, is identified and is identified as "structurally martensitic" - gardenain, which is a kind of classical martensite. Based on the analysis of a number of existing technological methods of strengthening the surface layer of structural materials, the dynamics of transformation of their microstructures was researched.
\end{abstract}

Keywords: laser treatment; microhardness; structural materials; technologies; X-ray reseach.

\section{Introduction}

With the development of modern processing technology, it was possible to control the physical and mechanical properties and the strong characteristics of structural materials. Strengthening of the surface layer of the part produced by through various variants of treatments, which involve the formation of strong and superstructure structures in the surface layer. Using the newest technologies of strengthening of steels it is possible to increase the microhardness of working surfaces of parts in times $\left(\mathrm{H}_{\mu 50}=2500\right.$ $13000 \mathrm{MPa}$ ), with their thickness $120-200$ microns. In the general approach, this is determined as the technological aspect of ensuring the reliability of friction units due to the impact on the original wear resistance of parts when manufactured. You should also take into account the following. Strengthened surface and, in case of surface layers of parts, more tribological joints of machine building objects operate in a lubricating environment, and in the initial stages of contact interaction they should be properly worked and ensure the formation of stable adhesive bonds with polyatomic molecules of various oils, for example, motor, transmission, etc. This directly affects the operational aspects of ensuring the wear resistance of materials when rubbed. Strengthening by using highly concentrated energy sources that are capable of modifying the surface layer of the component due to the density of radiation, high heating and cooling rates is achieved. In the result of these treatments superhard phases, microstructures and compounds are formed.

Of course, consideration of the direction of change in accordance with structures is advisable to proceed based on a generalized diagram of the structural strength of steels of different classes and ways to strengthen them, Fig. 1 [1]. The diagram shows the corresponding areas of destruction, which are located in the field of dependence of the Irwin criterion $\mathrm{K}_{\mathrm{ic}}$ on the current values of yield strengths $\sigma_{0.2}[1]$. The dashed line in the diagram indicates the value $\sigma_{0.2}=1400 \mathrm{MPa}$ that is the lower boundary of the endurance limit. A coincidence of high values $\sigma_{0.2}$ and $K_{i c}$ only with the use of thermomechanical treatment of martensite-aged steels (MAS), or essentially new (MAS, SMZ) steels is achieved. Proceeding from this, the promising direction of increasing the durability and wear resistance of steels is to combine several structural mechanisms of reinforcement by the usage combined methods of processing the surface layer of metals (surface treatment with high-frequency currents, ion implantation, laser treatment). The absorption of metals by laser radiation leads to an instantaneous increase in the energy of free and bound electrons. The energy of laser radiation into the motion of atoms, and the excited electrons collide with the lattice atoms is transformed (relaxation time is $10^{-12} \mathrm{~s}$ ). The rapid thermal removal in the depth of the metal contributes to the formation of a part of the special tempered structures in the surface layers. Observation of the changes in the physical and mechanical characteristics and the study of the microstructures of the corresponding zones of various technological steels using an electronic raster microscope REM106I was carried out [1]. In the investigation of the microstructure of the cast normalized steel, 45 there is observed a lamellar perlite and a ferrite network with sections of digestion of sulfur with cracks $(\mathrm{HB}=179)$, and after forging - a plastic perlite with a grid of ferrite, deflects 1,5 points (HB179-190) [2]. On hot-rolled steel 45 there is observed a lamellar perlite and a ferrite network at hardness of HB 217, and sorbitol (HB 285) is observed on the sample after sorption (hardening with high release). After 
quenching with cooling in water, the microstructure of steel 45 is transformed into an average needle martensite with microhardness HB 600-630, and in the hot-rolled metal of thickness $15 \mathrm{~mm}$ after hardening in the oil a microstructure of reed-martensite (HB 495) [2] is formed. If a leave to the last sample with the pre-treatment cycle, the transformation of the microstructure will lead to the formation of sorbitol $(269 \mathrm{HB})$ is observed.

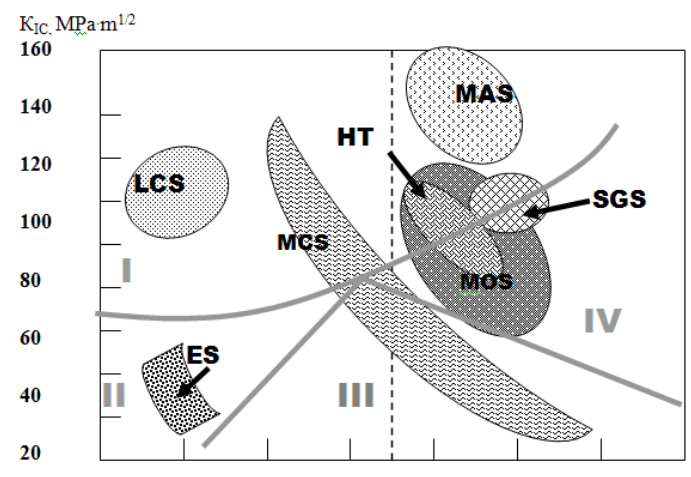

Fig. 1: Diagram of structural strength of steels:

MAS - metastable austenitic steels; SGS - a noble steel with a shallow grain; HT - steel after heat treatment; MOS - martensitic old steel: MCS medium carbon steel; LCS -low carbon steel; ES - Eutectic steels with lamellar perlite; I - the area of viscous destruction; II - region of transcrystalline chip; III - area of intercrystal chip; IV is the quasicleaved region [1].

The change of the heat treatment regime allows to control the processes of formation of the corresponding zones with certain microstructures of the surface layers, microhardness and physical and mechanical properties of the material of the part [2]. So after the quenching with subsequent cooling in the steel oil 45 a reed is formed in the ferrite (HB 311-321), and when the coil is cooled in water a reed-martensite and a ferrite with hardness HB 352 are formed. When surface is treated with high-energy sources (microwave) on surface of the details a white layer of structureless martensite with hardness HB 524 is formed. In the middle of the intersection of the part, a sorbitum with hardness HB 277-293 is observed in the depth of the surface [2]. As a result of the use of different types and methods of processing, it is possible to obtain different variants and variations of microstructures with corresponding physical and mechanical properties. But the further use of typical technologies to strengthen the surface layer is limited by certain features of the structure of the crystalline material lattice. Therefore, in recent times, widespread use of differentiated or combined processing of the surface layer of parts, which contribute to the emergence of gradients of the structuralphase state, and, consequently, uneven structure of the material. If necessary, the essential strengthening of the surface layer and the hardness of the material must be preconditioned to obtain the corresponding structures (martensite, carbides, nitrides, borides, etc.), which provides the specified properties. The purpose of local processing is to obtain soft, plastic structures (unsullied ferrite, austenite, sorbitol release of low carbon martensite) or vice versa - increasing the hardness of the surface layer in separate volumes. Thus, from studies of steel 45 as a result of general processing, the plastic structure of sorbitol was released, and after local hardening in differentiated treatment, the structure of martensite $\left(\sigma_{\mathrm{v}}=1200 \mathrm{MPa} ; \sigma_{0.2}=1050 \mathrm{MPa}\right.$ with reduced plasticity $\delta=10 \%$ ) [3]. For a significant increase in the hardness and wear resistance of individual local areas of the surface of the parts it is advisable to dip the metal with sources of concentrated energy, which sometimes increases the hardness of martensite and reproduces the strengthening phases (carbides, nitrides, borides, etc.). So in the steel $40 \mathrm{X}$ after preliminary cementation $\left(\mathrm{H}_{0-0.980}=\right.$ 5000-55000 MPa) and electron beam treatment (at $930^{\circ} \mathrm{C}$ for 4 hours), with the melting points of the respective sites and the total release by the microhardness of $\mathrm{H}_{0-0.980}=8000-12000 \mathrm{MPa}$ [3] were obtained. However, the question of evaluating the transformation of structures of average carbon steels, depending on the technological methods of strengthening, the identification of factors affecting the emergence of high-strength structures sufficient attention by the researchers was not given. In this scientific article the ensuring reliability the technological aspect of of friction units is observed.

\section{Presentation of the Main Research Material}

The purpose of the work is to identify the relationship of the original structure with the strengthened structure of the surface layers. The research using a metallographic and phase X-ray analysis was carried out. For researches, samples from materials of steel $45,50 \mathrm{HFA}$, cylindrical shaped, $4 \mathrm{~mm}$ thick, $35 \mathrm{~mm}$ in diameter and treated in the shaft-type nitrogen furnaces followed by laser treatment were used. Metallographic examinations of samples using the following microscopes were carried out:

- optical: MIM-7, "Neofot-21" with an interval of increase of 1000-4000 times;

- raster electronic: Cambridg Stereoscan-34 with an interval of 120-1000 times, an expanded PM-202M with the registration of images in secondary and reflected electrons with an increase of 720-15000 times, UEMV-100A - from 30000-54000 times.

$\mathrm{X}$-ray structural studies of working surfaces were carried out in monochromatized copper radiation on a X-ray diffractometer DRON-2 with the automated registration of diffraction spectra in the range of reflection angles $2 \Theta=20 \div 50$. Measurement of microhardness of the surface layers using the standard method of durometric analysis using the PMT-3 device at loads of 0.2-0.5 H was carried out. As a result of the processing of the received data, the following is established. Combined treatment - (nitriding) (Fig. 2) with the following laser treatment (pulsed laser GOS1001) provides formation in the surface layer of two highly nitrogenous phases: $\mathrm{Fe}_{3} \mathrm{~N}$ and $\mathrm{Fe}_{4} \mathrm{~N}$. These surfaces in the form of dense sections and massive streams cause high hardness of the surface layer of the nitrogen sample $(6870 \mathrm{MPa}$ for the surface and $4100 \ldots 4200 \mathrm{MPa}$ at a distance of $0.4 \mathrm{~mm}$ from it) [3-5]. The treatment of the phase state of the test steels was carried out by comparing (Fig. 3) the experimental sets of interplane planes with the corresponding data of the given phases (110) a-Fe; (111), (200), (220) $\mathrm{Fe}_{4} \mathrm{~N} ; \mathrm{Fe}_{3} \mathrm{~N}(100,002.001,102,110,103,112,201)$.

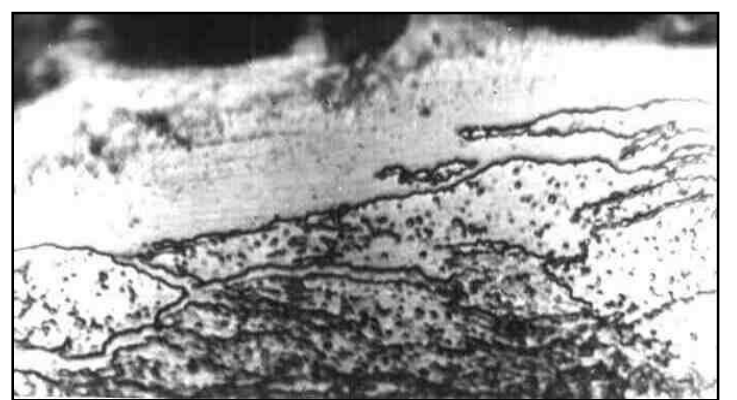

Fig. 2: Microstructure of the surface layer of the nitrided sample x 1000

X-ray diffractometric analysis of the nitrogen surface shows that the intensity of the (110) - Fe (ferrite) line, the most intense in the diffraction spectrum of pure iron, in the nitrogen sample is weakly detected [3].

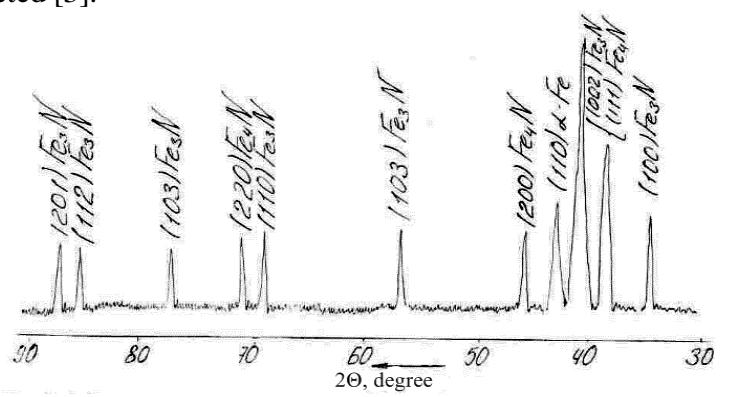

Fig. 3: The diffractogram of the surface layer of the nitrogen sample. 
The diffraction lines of the highly nitrogenous phase $\mathrm{Fe}_{3} \mathrm{~N}$ have the highest intensity. The intensity of the lines corresponding to the $\mathrm{Fe}_{4} \mathrm{~N}$ phase indicates its smaller volume fraction in the surface layer [4]. After laser treatment, due to the ultra-high velocity of cooling of crystallized volumes, due to intensive heat removal through the main volume of samples on the surface, a light zone (Fig. 4), which is not digestible, is identified and is identified as "structurally martensitic" - gardenain, which is a kind of classical martensite [5-7].
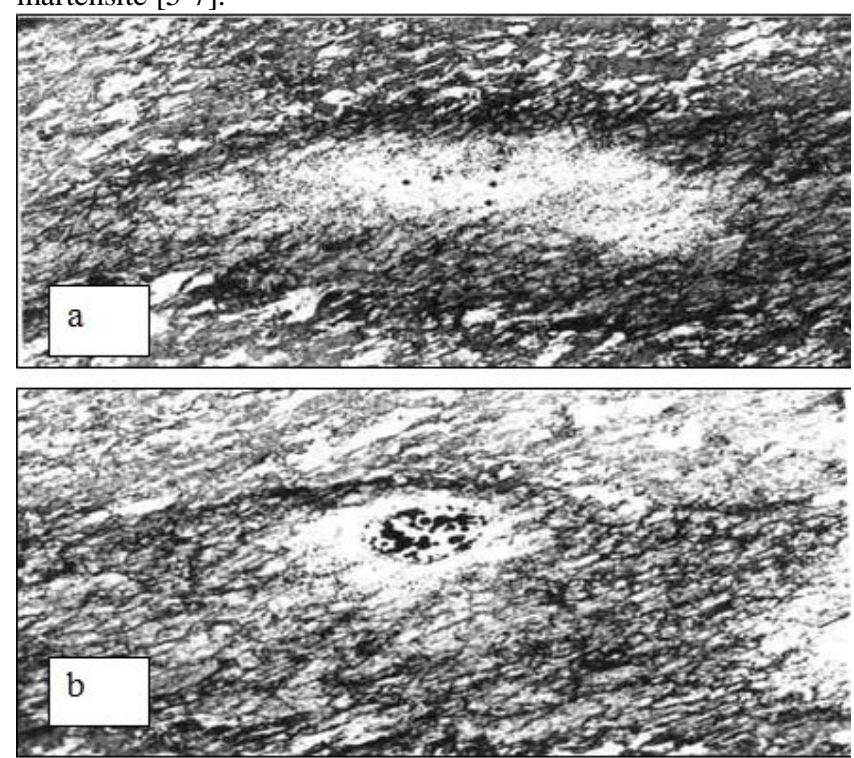

Fig. 4: Microstructure of machined surfaces of the working surface after laser treatment; a - x 50, b - x 100 .

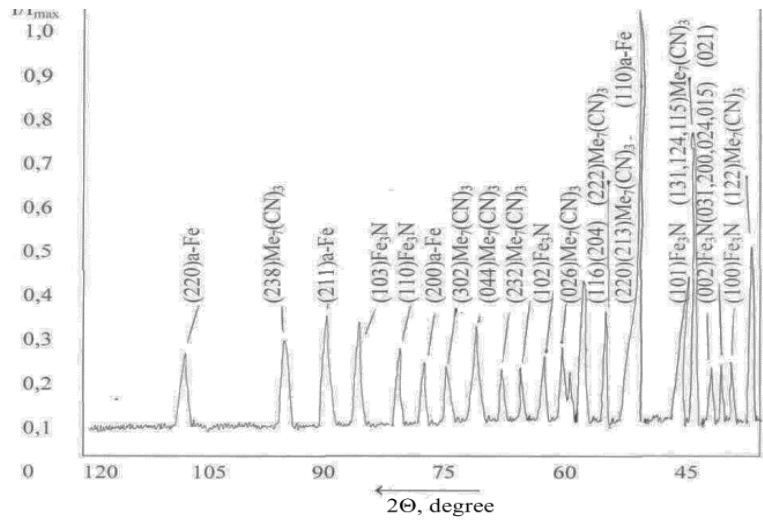

Fig. 5: The diffractogram of the working surface of the nitrogen sample with the subsequent laser treatment.

Thus, when laser treatment of nitrogen samples on the surface layer in the zone of laser influence, structures with high microhardness $\mathrm{H}_{\mu 50}=9277 \mathrm{MPa}$ be formed. The high microhardness of the gardeniate structure is also characteristic for porous inclusion with dark spots in the crater area. From the analysis of the phase composition of the nitrogen surface after the laser treatment of the surface, the following components occur: $a$ $\mathrm{Fe}$, carbonitrid type $\mathrm{Me}_{7}(\mathrm{CN})_{3}$, where $\mathrm{Me}(\mathrm{Fe}, \mathrm{Cr}, \mathrm{Mn})$, and nitride $\mathrm{Fe}_{3} \mathrm{~N}$. Note that $\mathrm{a}-\mathrm{Fe}$ - this is a gardenain of white spots and a ferrite of dark areas of the surface. The phase $\mathrm{Me}_{7}(\mathrm{CN})_{3}$ is a carbonitride with a complex orthorhombic lattice (prostrogroup group $D^{16}{ }_{2 h}=P_{p t a}$ in which part of the atoms positions carbon atoms occupy nitrogen. In the study, on the surface diffractogram, 13 lines (Fig.5) found in isomorphic phases of type $\mathrm{Mn}_{7} \mathrm{C}_{3}, \mathrm{Cr}_{7} \mathrm{C}_{3}$, $(\mathrm{Fe}, \mathrm{Cr})_{7} \mathrm{C}_{3}, \mathrm{Me}_{7} \mathrm{C}_{3}$ were found [10]. Arranged elements of fine structure in the form of needles and railing, plates (packages), according to martensite [8], formed in steels with a volumetric garret. The microstructures obtained with the help of an electron microscope UEMV-100A, Fig. 6 - 7, indicate that the laser formed on the surface of the samples as a result of laser radiation $a-F e$ has a structure with a high density of dislocations (of the order of $10^{11}$.
$10^{12} \mathrm{~cm}^{-2}$ ) and is characteristic of martensite. Arranged elements of fine structure in the form of needles and railing, plates (packs) $a-F e$ characteristic of martensite, formed in steels with a volumetric garret [7]. In the structure of martensite experimental samples are only accidentally detected, as shown in Fig. 8, connecting crystals - wide plates railing railing $a-F e$ - phases. On the electronogram and the location of the lattices, which crystallographically joins, is fixed. As the decryption showed, the voltage in the lattice (211) of one of the connecting crystals - the phase (Fig. 7a), parallel to the direction (100) of the second (Fig. $7 b$ ). For martensite, obtained by converted $\gamma \rightarrow \alpha$ as a result of laser radiation, the presence of micro-dwarfs in certain zones is characteristic [9-11]. Investigation of microstructures of tempered zones of microwave steel 45 using an electronic raster microscope REM-106I was carried out. The source material (Fig. 6a, b) has a microhardness $\left(\mathrm{H}_{\mu 50}=6000-6500 \mathrm{mPa}\right)$, a ferrite-pearlite structure in the basis and structures of quenching microwave with the inclusion of martensitic release [12].
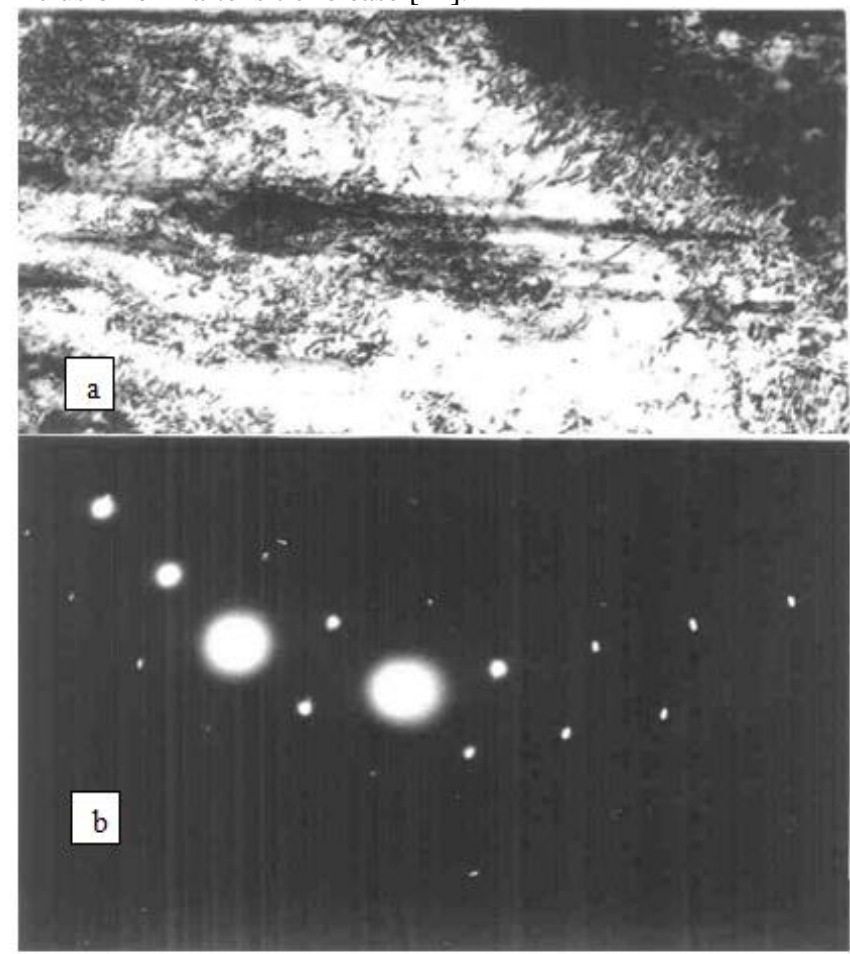

Fig. 6: Microstructure (a) and microdiffraction pattern (b) of the martensitic phase in the surface area of laser radiation spots - $x 36000 ; \mathrm{b}$ the axis of the electron band region (111).

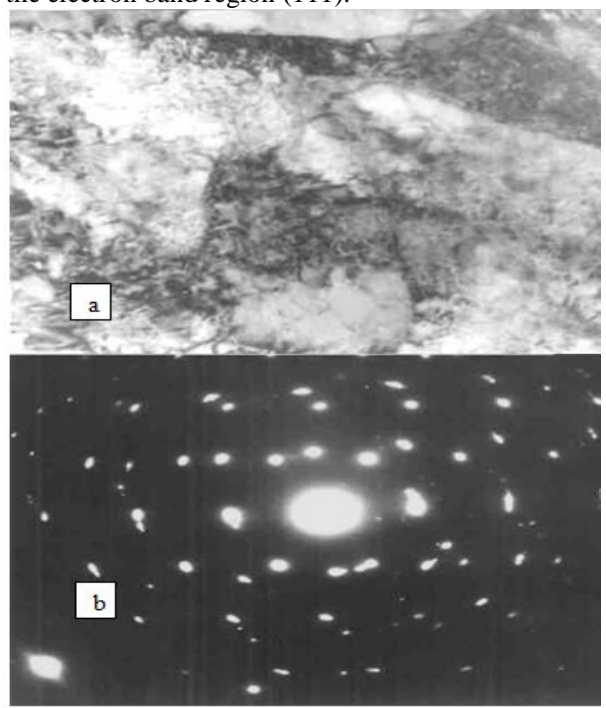

Fig.7: Microstructure (a) and microdiffraction pattern (b) of the martensitic phase in the surface area of laser radiation spots. a - x 54000; $\mathrm{b}$ - axis of the electron band (211) and (100); ratio of reference points (110)\|(114) two. 
The source material (Fig. 8a, b) has a microhardness $\left(\mathrm{H}_{\mu 50}=6000\right.$ $6500 \mathrm{MPa}$ ), a ferrite-pearlite structure in the basis and structure of quenching microwave with the inclusion of martensitic release [13].
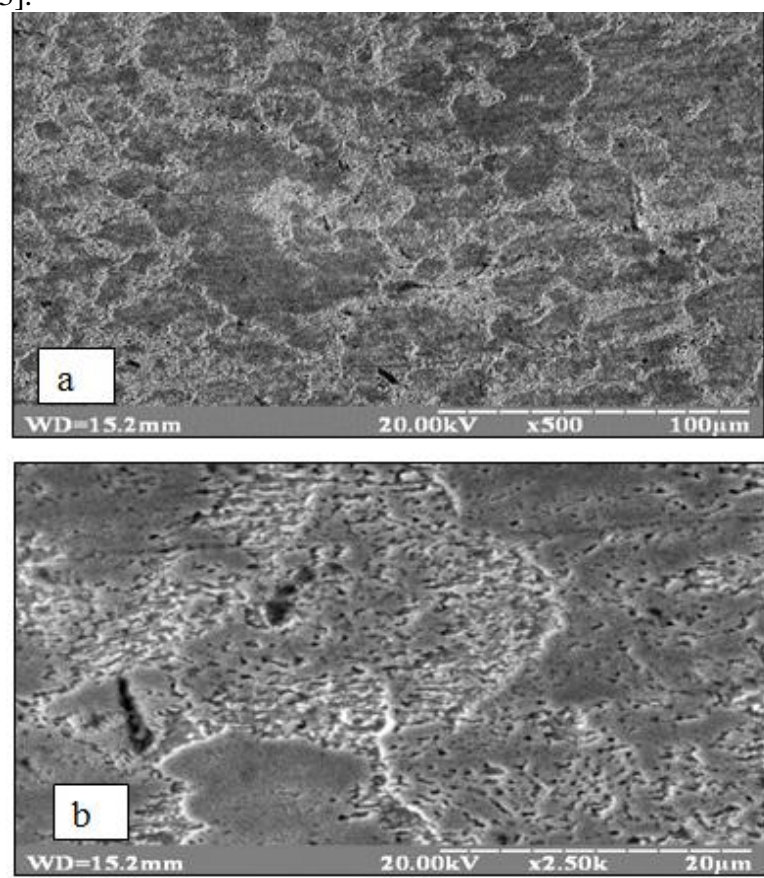

Fig. 8: Microstructure of the surface layer of steel 45 after heat treatment and microwave head.
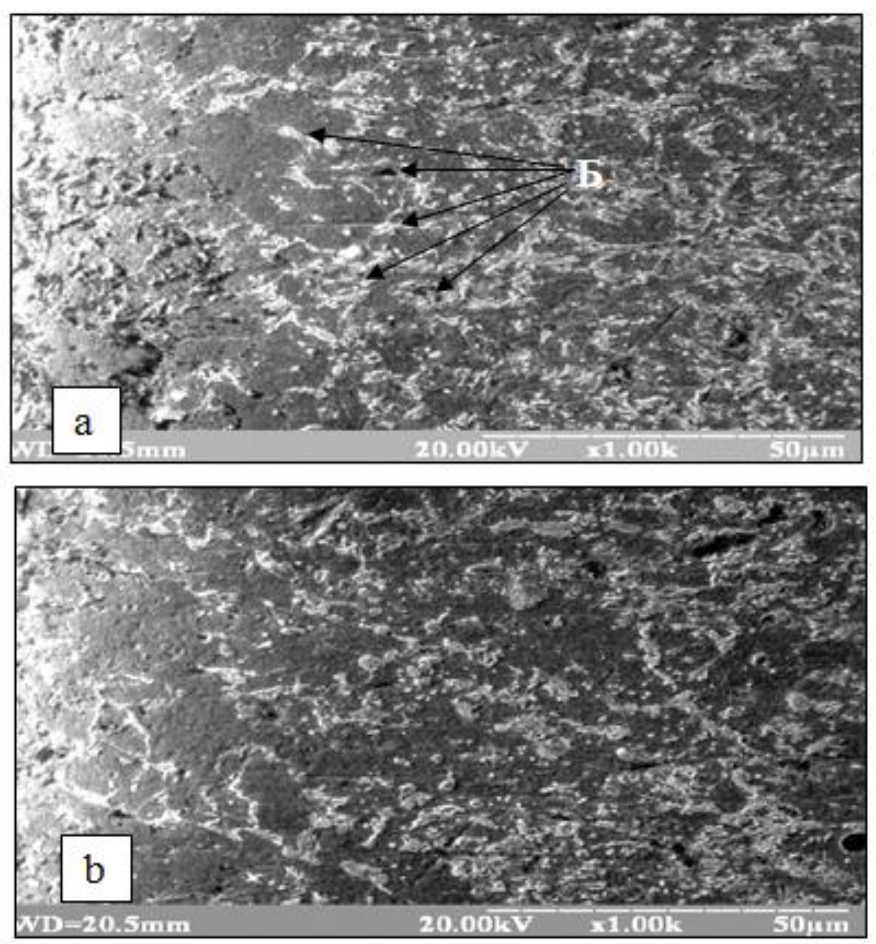

Fig. 9: Microstructure of the surface layer of steel 45 after heat treatment and microwave head.

The treatment of the deposited layer by boring [13] due to secondary heating and cooling, helps to shift the points of phase and structural transformations and the appearance of borides. Under the influence of cooling temperature gradients of there is anisotropy of crystals, elongation and orientation deep into the metal structural components (Fig. $9 \mathrm{a}, \mathrm{b}$ ). The form of structural elements of a metal corresponds to the type of structural elements of anisotropy of crystals. The surface has an elongated structure (Fig. 9 a, b) with white inlays of borides, the size of which ranges from 100-150 $\mu \mathrm{m}$ [13]. Thus, in the structure of the transformed surface, there is a perlite structure with carbide impregnations
(Fig. 9 a, b.). The layer itself has a depleted carbon structure with particles of carbides whose size varies within 0.5 microns.

Figure 10 shows the graphic model of the dependence of the hardness of the surface layer 45 on the technological strengthening methods of treatment on which it is possible to observe the dynamics and transformation of the microstructure on which the physical and mechanical properties of the working surface of the steel 45 are dependent [14].

\section{Conclusion}

Based on the analysis of a number of existing technological methods of strengthening the surface layer of structural materials, the dynamics of transformation of their microstructures was determined. The graphic model of the dependence of the hardness of the surface layer of steel 45 on the strengthening of surface treatment technologies has been developed, which allows us to find the optimal reinforcement technology with the corresponding physical-mechanical characteristics and properties of the surface layer of steel 45 parts. Surface structures obtained for steel 45 are considered interesting from the point of view ensuring the predicted strength of the surface layer of the parts working surface and of the regularities of the formation of stable lubricant formations from components. This is the main goal of our further research work.

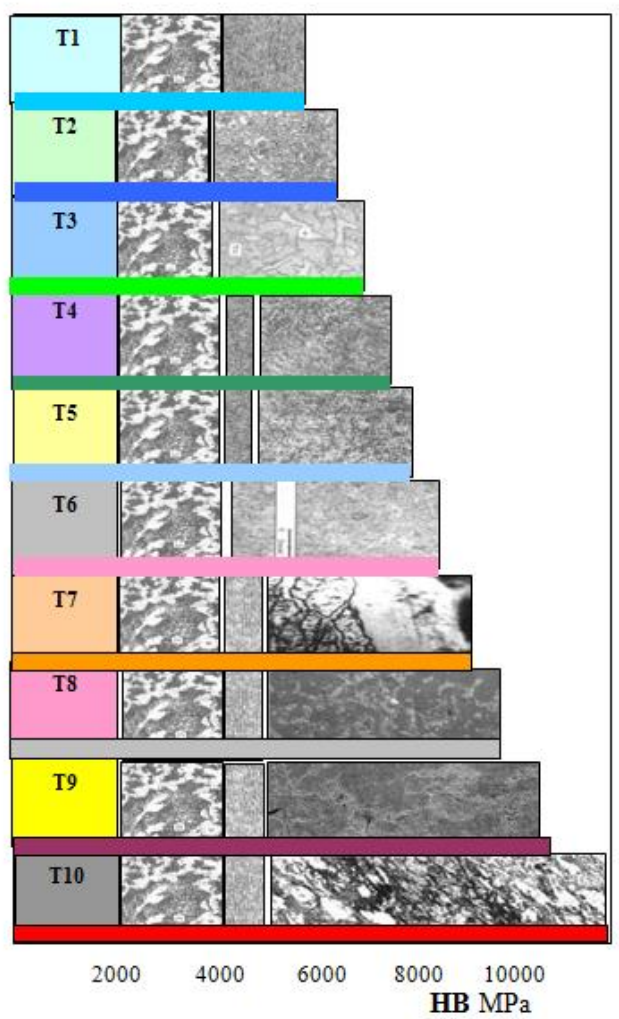

Fig. 10: Graphic model of the dependence of the hardness of the surface layer of steel 45 on the technological strengthening methods of treatment (T1-sorption;

T2-hardening with cooling in the lubricant - reed and ferrite;

T-3 - cooling with water - trostomartensite and ferrite;

T4 - T6 - microwave - unstructured martensitic;

T7 - after nitriding - high nitrogen phases - nitrides $-\mathrm{Fe}_{3} \mathrm{~N}, \mathrm{Fe}_{4} \mathrm{~N}$;

T8 - boring with the formation of borides;

T9 - nitriding - hardening of microwave - martensite;

T10 - nitriding following by laser treatment - gardenite with carbonitride zones and nitrides such $\mathrm{Fe}_{3} \mathrm{~N}$ ). 


\section{References}

[1] A.G. Suslov, Y.V. Gulyayev, A.M. Dalsky and others, Quality of machines, Handbook. T2 M. Mechanical Engineering (1995), pp: 43-58.

[2] I.V, Fransenyuk, L.I. Fransenuk, Album of microstructures of cast iron, steel, non-ferrous metals and their alloys, -M.: ICC "Akademkniga", (2004), pp: 135-138.

[3] L.S. Malinov, "Differential treatment of alloys to enhance their properties is a promising direction in material science", New materials and technologies in metallurgy and mechanical engineering, Scientific journal No.2, (2012), pp: 50-56.

[4] J.M. Poate, G. Foti, D.C. Jacobson, Surface modification and alloying by laser, ion, and electron beams, M. Mechanical Engineering, (1987), pp: 301-302.

[5] Hu W.W., Herman H., Clayton C.R, Ion Implatation Metallurgy, ed. G.M. Preece and J.K. Hirvonen New York: TSM-AIME, (1980), pp: $100-102$.

[6] O.G. Cherneta, R.G. Voloshchuk, A.N. Korobochka "Research of technological methods of formation of wear-resistant coatings on the basis of laser treatment", Collection of scientific works "Perspective Technologies and Devices", city Lutsk November 2014 - Lutsk: LNTU, - Vol.5 (2), (2014), pp: 171-176.

[7] ASTM Card File (Diffraction Date Card and Alphabetscal and Grouped Numerical Index of X-Ray Diffraction Date) Philadelphia; E d. By ASTM, (1969).

[8] A.S. Zavyalov, G.N.Teplukhin, K.V. Gabayev, Conditions and mechanism of formation of unstructured martensite (gardenite), Metallurgy and thermal processing of metals, No.10, (1979), pp: $11-12$.

[9] V.K. Grigorievich, Hardness of the hardness of metals, -M. Science, (1976), pp: 230-232.

[10] O.G. Cherneta, I.O. Babko, Y.V. Chaldyshev, "Research of technological methods of formation of wear-resistant coatings on the basis of laser treatment", Collection of scientific works "Perspective Technologies and Devices", Vol.5 (2), (2014) pp: 176179

[11] O.G. Cherneta, V.I. Sukhomlin, R.G. Voloshchuk, B.P. Sereda, "Investigation of microstructure of worn parts of automobiles made of steel 45 when restored and repeated thermal treatment", Perspective technologies and devices. Lutsk / June 2017 - LNTU, Vol.10 (1), (2017), pp: 212-217.

[12] O.G. Devoyo, Technology of forming wear-resistant surfaces by laser doping, Minsk: UP "Tehnologiya", (2001), pp: 80-87.

[13] B.P. Sereda, N.E. Kalinina, I.V. Kruglyak, Surface reinforcement materials, Monograph, Zaporozhye: Publishing house of Zaporizhzhya State Engineering Academy, (2004), pp: 230.

[14] O.G. Cherneta, V.I. Sukhomlin, A.N. Korobochka, "Research of the microstructure of worn parts of automobiles made of steel 45 when restored and repeated thermal treatment", Perspective technologies and devices, Vol.10 (1), (2017), pp: 222-217. 